\title{
SELECTED STRUCTURAL ISSUES OF THE WATERJET METHOD IN INDUSTRIAL RECYCLING OF TIRES
}

\author{
H. Holka*, T. Jarzyna**
}

\begin{abstract}
The study deals with structural problems which have a significant influence on effective application of Waterjet method management in materials recycling of tires. The authors, on the basis of long term tests of this recycling method and analysis of other available solutions, provide guidelines for application of Waterjet technology so as to attract attention of potential investors.
\end{abstract}

Keywords: tire recycling, Waterjet method, Waterjet technology, environmental protection

\section{Introduction}

Widespread application of pneumatic tires in automotive vehicles started in 1905, and in trucks in 1930 . Since that time the automotive industry has developed significantly which is reflected by a large supply of car tires (nearly $1 \mathrm{mld} \mathrm{Mg}$ annually), which need to utilized in some way (Wojciechowski, 2014). Information on the subject of used tires management can be found in work (Holka\&Jarzyna, 2017).

From among available recycling methods, mechanical comminution is quite commonly used. Disadvantages of this method include its energy consumption and noisiness. It results from difficulties posed by recovery of rubber from car tires caused by their resistance to external forces, high strength, and elasticity. Waterjet method which uses a high pressure water jet to process a tire is interesting and innovative. This method involves using energy of a water jet running against tread surface which causes almost ideal separation of steel wires from the remaining materials of the tire (Verri, 2011). It is an unquestionable advantage of this technology as compared to other methods of mechanical grinding. Moreover, the treatment involves only one cycle. Apart from recycling, Waterjet technology has many other applications, e.g. to provide miniature samples for static and fatigue tests. This results from noninvasive impact on the processed material (Tomaszewski et al., 2016).

Research on the subject of Waterjet technology has been conducted at the University of Science and Technology for several years. Although experimental tests have proven effectiveness of this method there are still many problems that need to undergo further analysis. This may be the reason why application of this technology in the world tire recycling is limited and potential investors are cautious about investing own funds for further research and subsequently implementation of this technology in industry. Thus, the author's article has made an attempt to compare selected results of their own works with interesting worldwide solution in the field of Waterjet technology.

\section{Waterjet technology in tire recycling}

Finding appropriate and optimal technology with the use of Waterjet method basing on very general patent presumptions (Holka, 2011) is very difficult and first of all time consuming.

\footnotetext{
* Prof. Henryk Holka, PhD.: University of Bydgoszcz, Unii Lubelskiej 4C Street; 85 059, Bydgoszcz; PL, hhenryk@vp.pl

** Tomasz Jarzyna, PhD.: Institute of Mechanics and Machine Design, University of Science and Technology; Al. prof. S. Kaliskiego 7; 85 796, Bydgoszcz; PL, tomasz.jarzyna@utp.edu.pl
} 
At the beginning of experimental tests, it seemed that the best method of the rubber separation from the wire is application of a singular water jet to the entire head part of the tire, like in the process of turning. For appropriate rotational speed of the tire and adequate feed (is an equivalent of a turning knife), the Fig. 1. Another problem is deflection of the tire under the influence of high water pressure. The issues connected with identification of reaction forces occurring in the contact between the susceptible are addressed in works, e.g. (Piątkowski, 2008 and Piątkowski, 2009).
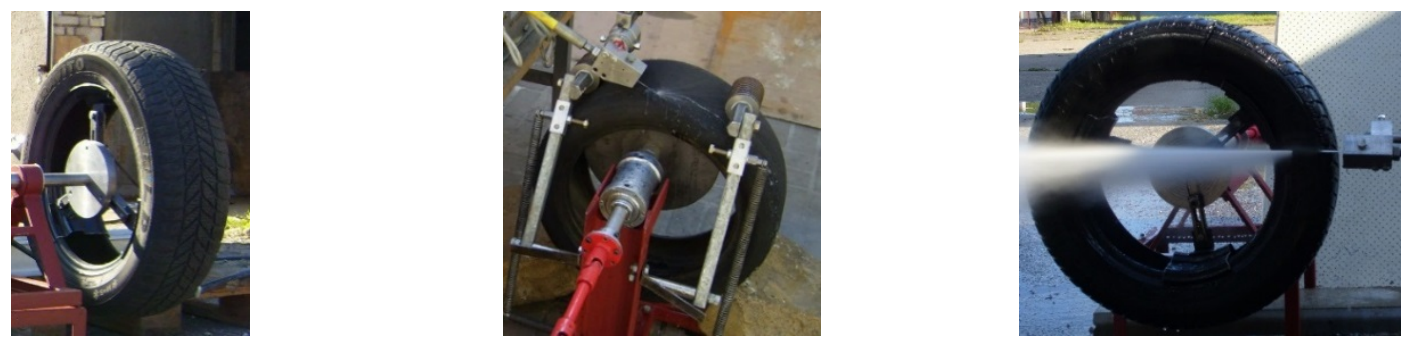

Fig. 1. Tests with the use of single water jet directed onto a tire.

Efficiency of single water jet treatment of a tire depends on many factors including: diameter of nozzle, pressure of the water jet, its distance from the tire surface, relative speed of the nozzle, angle between water jet and the tire surface. Adequately matched parameters provide benefits in the form of operation efficiency and economic profitability. For instance, for water jet pressure $\mathrm{p}=200 \mathrm{MPa}$, the output of a nozzle with diameter equal to $\mathrm{d}=1 \mathrm{~mm}$ is 2.75 higher than a nozzle with $\mathrm{d}=0.6 \mathrm{~mm}$, for similar quality of the process. Therefore, in result of studies and calculations, it was established that application of nozzles with diameters $\mathrm{d}=0.4-0.6 \mathrm{~mm}$ is most beneficial. In the case of the jet angle, the bests results are to be achieved for its small values, when $\alpha \approx 0^{\circ}(\alpha-$ angle measured between a nozzle and the normal in relation to the tire surface). Moreover, it was found that for $\alpha \approx 70^{\circ}$, the tire treat cutting follows which leads to reception of $30 \mathrm{~mm}$ wide straps. Higher values of the angle are accompanied with cutting of rubber layer and the wires of reinforcement are inaccurately cleaned. Through rubber cutting was reached for $0^{\circ} \leq \alpha \leq 50^{\circ}$. As regards water pressure, it is found that the output of rubber cutting grows along with its increase. In work (Hu et al., 2014) the authors investigating the rubber cut depth, find that it is mostly affected by water pressure. Due to energy consumption and water use it is established that the most optimal pressure to be used in the process of tire cutting is $p=200 \mathrm{MPa}$. Analyses of the nozzle distance from the tire surface show that this is distance $h=20 \mathrm{~mm}$, that is the most suitable though the highest energy of the water jet is found to $1 \leq 5 \mathrm{~mm}$ from the nozzle outlet.

Experiments show that for the process optimal parameters it is possible to obtain significant rubber comminution degree (mean value of dimensions: $146 \mu \mathrm{m}$, dimensions of $67.3 \%$ of the population were 9-159 $\mu \mathrm{m}$, spread of measurements $\mathrm{R}=709-9 \mu \mathrm{m}$ ). The obtained results are better than for the method of mechanical grinding.

Using the most effective parameters for a single jet $(\mathrm{p}=200 \mathrm{MPa}, \mathrm{h}=20 \mathrm{~mm})$, tests were repeated with the use of a three-head nozzle (Fig. 2). Complete separation of rubber from reinforcement was found and steel wires were not damaged (Fig. 3). The suggested stroke speed is $v \geq 0.0055 \mathrm{~m} / \mathrm{s}$.
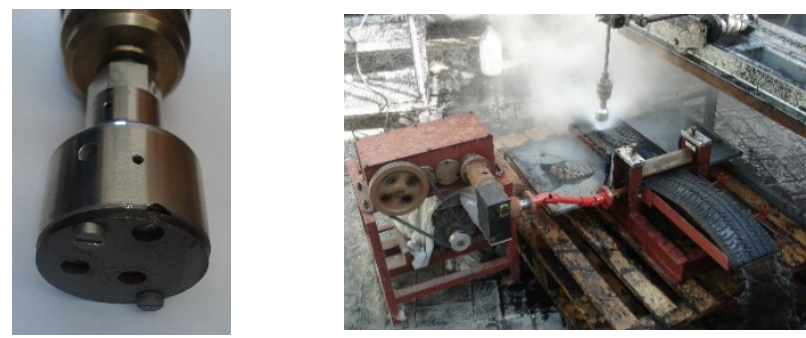

Fig. 2. Overall view of three-nozzle spray head.

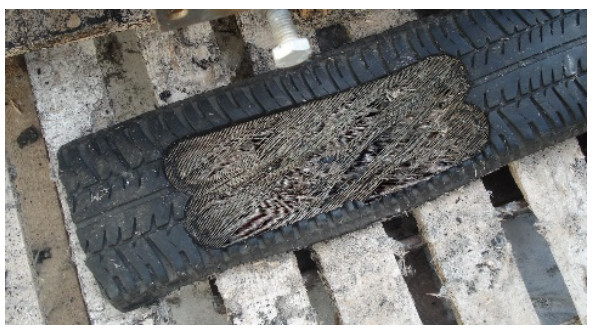

Fig. 3. View of a tire after application of three-nozzle spray head.

Using three-nozzle spray heads for tire rubber comminution a demand for the process energy needs to be considered. For the process parameters $\mathrm{p}=200 \mathrm{MPa}$ and $\mathrm{h}=20 \mathrm{~mm}$, a $50 \mathrm{~mm}$ wide strap is received form the tire. It means that in order to handle a $200 \mathrm{~mm}$ wide tire a set of four parallel three-nozzle heads has to be applied. A diagram presenting power demand for a single three-nozzle head and a system of four heads depending on different diameters of used nozzles is depicted in Figure 4. 


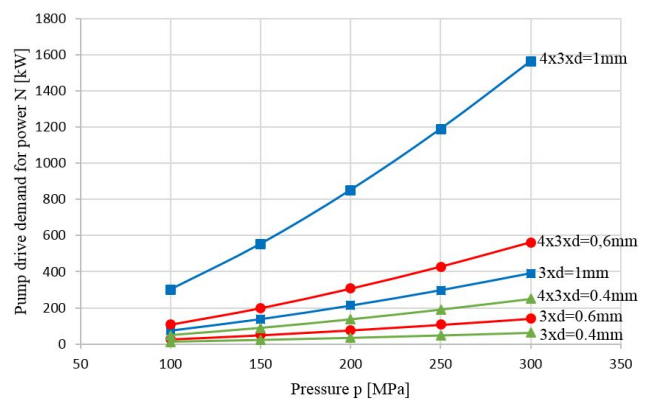

Fig. 4: Dependence of power demand for the pressure pump drive.

Having analyzed the figure, it can be seen how the process energy consumption is reflected by the nozzle diameters and the number of heads. It is possible to reduce energy consumption through optimization of the process. Further research on changing the head distance from the surface tire needs to be done which would find reflection in the width of the processed strap and the nozzle diameters. The author of work (Blair, 2003) suggests using nozzles with diameters equal to 0.1-0.25 mm.

Due to the importance of the distance between the head and the tire, a solution was developed to be used for maintenance of its constant value during the process. For this purpose, a patent application was submitted with a proposal of a system for monitoring the distance between the front of a high pressure water jet head and the tire surface (Fig. 5).

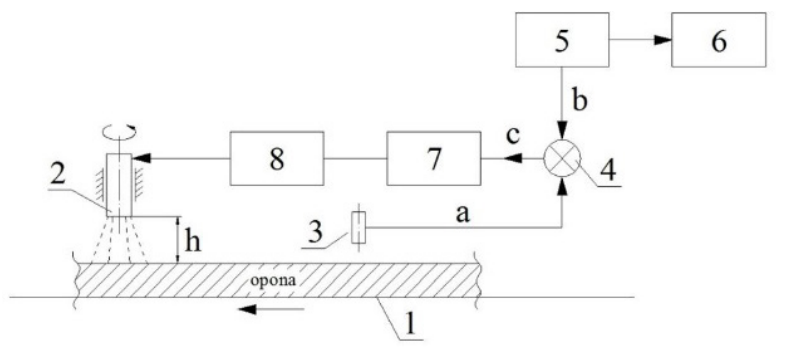

Fig. 5. System of automatic head positioning toward the tire: 1 - tire, 2-spray head, 3 -laser height sensor, 4 -summation node, 5 -controller, 6 -operator's terminal, 7 -servomotor, 8 -operating system, a-channel connecting sensor (7) with summation node (4), $b$-channel connecting controller with summation node, $c$ - resultant channel connecting servomotor with summation node.

The proposed method involves earlier separation of the tire sides from the treat and its one cycle treatment by means of a water jet. Two stage process with the use of abrasive and rotary heads is proposed in work (Rutherford, 1992), Fig. 6. In the first stage, as much as $50 \%$ of the tire materials is separated and in the second stage the remaining ones undergo separation. Apart from the above mentioned solution, the author of this work has presented other ideas for treatment of entire tires. A description of a recycling method for tires cutting and flattening before treatment can be found in literature (Karwecki, 2013). The treatment method described in this solution uses nozzles fixed to transversely vibrating bars. In another solution (Rutherford, 1994) a tire is placed on a rotary lower platform (Fig. 7), whereas water jets come from a few heads placed on an upper platform (Fig. 8).

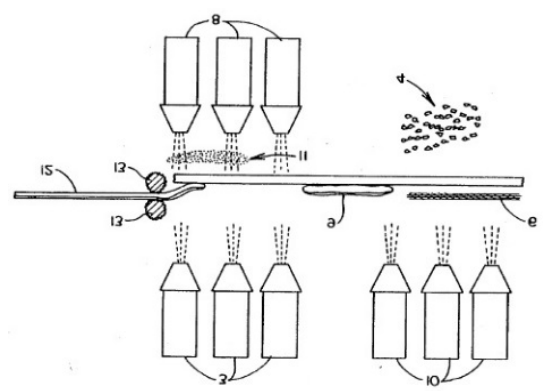

Fig. 6. Two stage treatment of a flattened tire: 3, 8 -water jests of the first stage of the process, $4-$ larger pieces of comminuter rubber, 6 - purified material of the tire cord, 9 -remains of the tire after the first stage of the process, 10 - water jets of the second stage of the process, 11 -smaller pieces of comminuted rubber, 12 -flattened tire, 13 - rollers. 


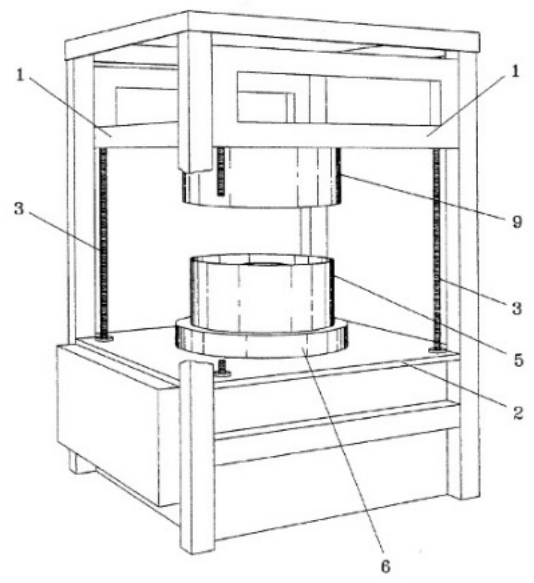

Fig. 7. Device for the recycling process: 1 -upper platform, 2-lower platform, 3-screws, 5-external cylindrical element, 6 - collar, $9-$ cylindrical element.

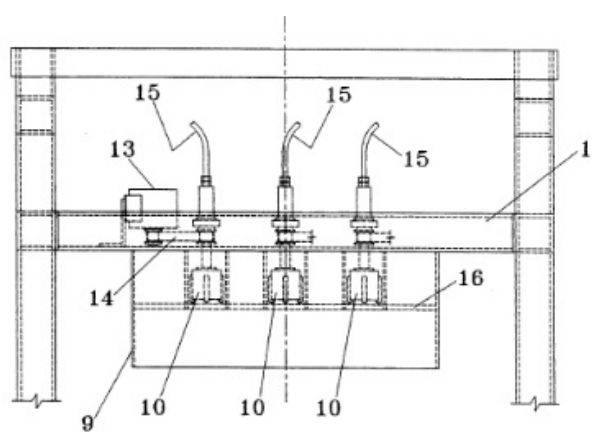

Fig. 8. Upper platform of the device: $1-$ upper platform, 9 - cylindrical element, $10-$ nozzle head,13 - drive motor, 14 - drive belt or chain, 15 - high pressure pipes.

\section{Conclusions}

1. Although the proposed tire treatment method by means of spray heads is a method which has been explored so well that it can be used in practice, it still requires further optimization research.

2. Separation of the tire blocks make the process of recycling much easier. Since the blocks do not contain a wire grid they can easily be grinded in typical mills.

3. Regardless of the applied treatment method the granulate contains textile fractions which must be separated from the rubber.

\section{References}

Blair, D., The disintegration of rubber tyres using ultra high pressure fluid jets. International Publication Date: 17.07.2003, International Publication Number: WO2003057442 A1.

Holka, H. (2011), Method of tires utilization. Patent No. 207101.

Holka, H., Jarzyna, T. (2017) Recycling of car tires by means of Waterjet technologies. AIP Conference Proceedings, 1822, pp. 020008.

Hu, Y., Kang, Y., Wang, X.-C., Li, X.-H., Long, X.-P., Zhai, G.-Y. and Huang, M. (2014) Mechanism and Experimental Investigation of Ultra High Pressure Water Jet on Rubber Cutting. International Journal of Precision Engineering and Manufacturing, Vol. 15, No. 9, pp. 1973-1978.

Karwecki R. (2016) Method and device for grinding used tires. Patent No. 223338.

Piątkowski, T. and Sempruch, J. (2008) Model of the process of load unit stream sorting by means of flexible active fence. Mechanism and Machine Theory, 5(43), pp. 549-564.

Piątkowski, T. and Sempruch, J. (2009) Model of inelastic impact of unit loads. Packaging Technology and Science, John Wiley \& Sons, 1(22), pp. 39-51.

Rutherford Sr. D. (1992), U.S. Patent No. 5,115,983.

Rutherford Sr. D. (1994), U.S. Patent No. 5,341,996.

Tomaszewski, T. and Strzelecki, P. (2016) Study of the size effect for non-alloy steels S235JR, S355J2+C and acidresistant steel 1.4301. AIP Conference Proceedings, 1780, pp. 020008.

Verri R. Scrap tire recycling plant. Publication number: US 2011/0163190 A1, Publication date: 07.07.2011.

Wojciechowski, A., Żmuda, W. and Doliński, A. (2014). Thermal decomposition of tires and residual char utilizing. Logistyka, 6, pp. 11278-11288. 